\title{
IMPROVING EFFICIENCY OF ZINC COATING SECTION OF CONTINUOUS GALVANIZING PRODUCTION LINE USING QUALITY TOOLS
}

\author{
H Prashanth ${ }^{1}$, Chitriki Thotappa ${ }^{2}$ \\ ${ }^{I}$ Student, Master in Technology, Production Management, RYMEC, Ballari \\ ${ }^{2} M E$, Phd, Professor and PG Coordinator, Mechanical dept., RYMEC, Ballari
}

\begin{abstract}
Improving the efficiency of any system is a add value to the organization, especially in continuous production system. This paper aims at improving the efficiency of zinc coating section of continuous galvanizing line in a steel plant using QC tools.Galvanizing is a technique of smearing a protective Zinc coating on Steel or iron, to avert its rusting. The usual practice to produce galvanized steel is through hot dip galvanizing method. It is a continuous line where annealed sheet is immersed into molten Zn bath with Sink roll assembly guiding the sheet and air knife system maintaining proper coating of Zn onto the sheet and is passed through temper mill to impart required roughness on to it. Due to high vibration at sink roll assembly, sink roll bushes get wear frequently and scratches are formed on sheets, as a quality defect. The purpose of this paper is to identify the vibration causing element and minimize it, which reduces the sink roll changing frequency and increase Zn coating section availability time. And also minimizes the scratch formation on sheet during coating. Every Sink roll assembly changing takes four hours and complete line needs to be down, hampering the production. The data were collected, analyzed and implemented to increase the availability time of $Z n$ coating section. Cause and effect analysis and Pareto analyses have been carried out and found that Corrector and Stabilizer roll shaft inclination found to be the root cause for high vibration high vibration by analyzing through Cause and Effect diagram and Pareto analysis, so same has been modified to non drive and sink roll bush thickness increased accordingly to get grater production cycle of sink roll.
\end{abstract}

Keywords: Corrector and Stabilizer roll, Cause and effect analysis, Dross formation, Hot dip galvanizing, Pareto analysis, Sink roll assembly vibration, Zinc coating

\section{INTRODUCTION}

Galvanizing is a technique of coating a protective Zinc coating on Steel or iron, to prevent it's rusting. The usual practice to produce galvanized steel is through hot dip galvanizing method Zinc acts as an sacrificial material protecting the base metal iron from corroding or when scratch is formed. Hot dip galvanizing is a continuous process in which sheet is cleaned by alkali solution to remove coolant and other dust particles, generally cleaned by alkali solution, metallurgical changes is acquired by annealing, annealed sheet is immersed in molten $\mathrm{Zn}$ bath and passed through tempered rolling mill to induce require roughness on sheet and alter the elongation point of sheet to some extent. Its annual production is approximately 25000MTPA.

Being continuous process, downtime of equipment will affect the complete process and productivity in one or other way. Sink roll assembly, which guides the annealed sheet through molten $\mathrm{Zn}$ bath is an vital equipment of Galvanizing line and as assembly will be completely in molten Zinc environment, it need to be changed frequently to maintain quality coated steel. Every sink roll change need 4 hours from stop to start of the process and frequent changing of assembly ultimately increases line downtime and decreases productivity. Hence minimizing sink roll changing frequency increases the line availability tome for production

\section{LITERATURE SURVEY}

Till date lot of research has been conducted for effective utilization of $\mathrm{Zn}$ coating section at galvanizing line which provides positive results towards profitability \& customer satisfaction at the respective work areas. The approach of all the researches was same as to increase the line availability time with respect to coating section by reducing sink roll assembly changing frequency and controlling mechanical failure of auxiliary units. Productivity can be increased by adopting practices to reduce downtime that will ultimately increase available time. In order to properly diagnose a defect, it is necessary to investigate all manufacturing steps, final inspection and customer claims. It is essential to reducing delays by defining corrective and preventive actions. First by Pareto analysis we can sort all different defects with their relative significance to the total rejection. Then Root Cause Analysis can be used to perform a comprehensive, systematic review of critical incidents. It includes the identification of the root and contributory factors, determination of risk reduction strategies, and development of action plans along with measurement strategies to evaluate the effectiveness of the plans. It is an 
important tool for a thorough understanding of "what happened". A root cause is the most basic reason for an undesirable condition or problem. If the real cause of the problem is not identified, then one is merely addressing the symptoms and the problem will continue to exist

Pratik J Patel and Sanjay Shah studied that if manufacturing industry is taken into account; quality control tools have been used to study and improve quality taper shank drills [1] by studying whole process and applying QC tool in every stage of process.

Irena Ograjenšek, an economist have proposed to companies to adopt the TQM and use these QC tools to increase the service factor in overall [2], as service accountability is more than $75 \%$ in most developed country. Chiragkumar S.and Chauhan studied with bearing industries, rejection and rework being major concern in these industries, QC tools has been used to minimize the same, especially with taper roller bearing [3]. In hot dip galvanizing, coating quality, weight and thickness being crucial part of processes, many models have been proposed to get the good control over it. Kazunari Andachi and Harumi Shigemoto proposals focused on gas wiping methods where excess coating is wiped off by when gas blow through nozzles.[4] Yeon Tei,xyz,etl proposed an apparatus and also formulated a mathematical model which interlinks the process parameters and helps to get control on coating thickness[5]. Stefania Salokyova, xyz,etl studied the impact of vibration on rate of change technical state of a machine. It has been carried out on a Lathe machine by linking three parameters viz. machining precision, noise level of machine and resizing of electricity on too machine with the technical state of machine. These three criteria have been analyzed using Signal Express Software to convert them into statistical data and by analyzing it is occluded that rate of change of technical state is directly proportional to size of vibration. [6]

Galvanized steel in present era plays a important role in everyday lives. It has various filed usage of transport, construction, power transmission, and where ever long life is needed, graphical representation is shown in Fig 2.1.Zinc being vital for human health and ecosystems is effectively recyclable and it is a key raw material for hot dipgalvanizing.

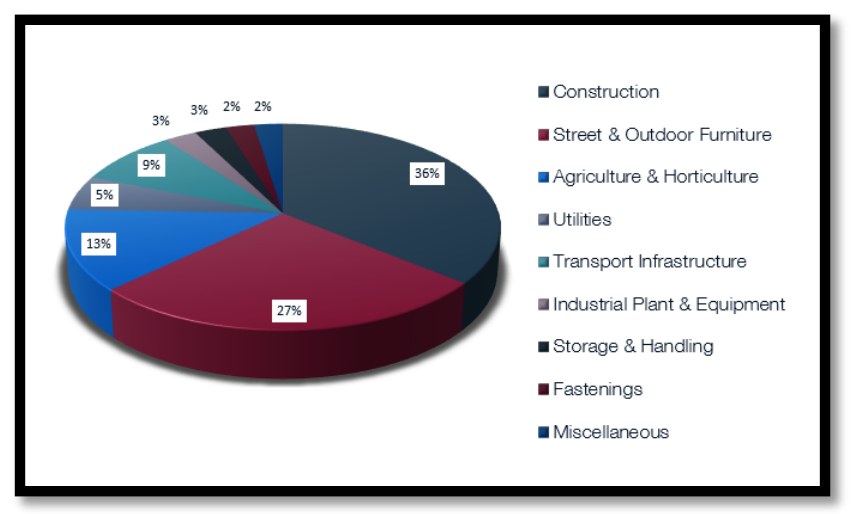

Fig 2.1: Application of Galvanized Steel

\section{PROCESS DESCRIPTION}

\subsection{Line Description}

The hot dip galvanizing line includes annealing furnace and rolling mill as a important section other than Zinc coating section which serves the purpose of relieving internal stresses and imparting roughness of galvanized sheet. One of the most important characteristics of the such line is that nearly half of the product mix is for the automotive outer panels that require a high level of surface quality. The justin-time oriented coil schedule is established to meet customer orders. As a result, due to the wide product mix, the jet stripping system experiences many thicknesses, grades, line speeds and of course, coating weight transients.

\subsection{Hot Dip Galvanizing}

Preheated steel strip coming from the annealing furnace is passed through a molten zinc bath at $460^{\circ} \mathrm{C}$. The thickness of the film deposited on to the strip as it emerges from the bath is controlled by jet stripping, which consists in forcing excess zinc to flow back in to the bath by directing a high velocity and horizontally extended gas jet at the moving strip (Fig 3.1).

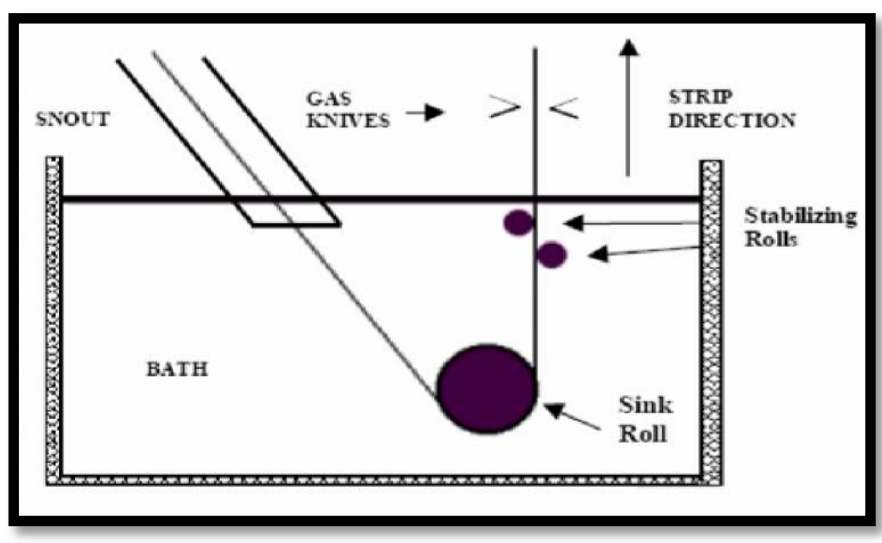

Fig 3.1: Zn pot overview

\section{PROBLEM DEFINITION}

Zinc Coating section being heart of Continuous Galvanizing line, its downtime hampers the production to a great extent. As sink roll and its auxiliary units are immersed in molten $\mathrm{Zn}$ bath, this assembly is to be change frequently to get effective performance and quality of coating. Every sink roll change takes 4 hours and it is being carried out every ten days once. Assembly changing frequency is to be decreased so that line availability time will be increase and thus productivity. By problem categorization and priority index it's been identified that high vibration of sink roll assembly is leading to wear and tear of sink roll bushes and further increasing the vibration. Decreasing this vibration causingelement will increase effectively of sink roll assembly by decreasing its changing frequency. $2.5 \mathrm{~mm} / \mathrm{s}$ is the allowable vibration and collected vibration reading is tabulate in Table 4.1 
Table 4.1: Average of vibration readings prior modifications

\begin{tabular}{|l|l|l|}
\hline Sl no. & Point no. & Vibration value in \\
\hline 1 & Point 1 & 2.64 \\
\hline 2 & Point 2 & 2.46 \\
\hline 3 & Point 3 & 2.43 \\
\hline 4 & Point 4 & 2.41 \\
\hline
\end{tabular}

\section{MINIMIZING THE VIBRATION}

By carrying cause and effect analysis(Fig 5.1) three main causes been validated which is adding to high vibration, those are drive shaft unbalancing problem, high inclination angle of drive shaft and material composition problem of drive shaft. Two drive shaft here is of Stabilizer and Corrector roll of sink roll assembly. After conducting brain storming session with all concerned persons, Stabilizer and Corrector roll drive system is modified to non-drive and sink roll bush thickness have been increased from $10 \mathrm{~mm}$ to 25 $\mathrm{mm}$. PDCA methodology is used to implement the solution and vibration reading post modification is tabulate in Table 5.1

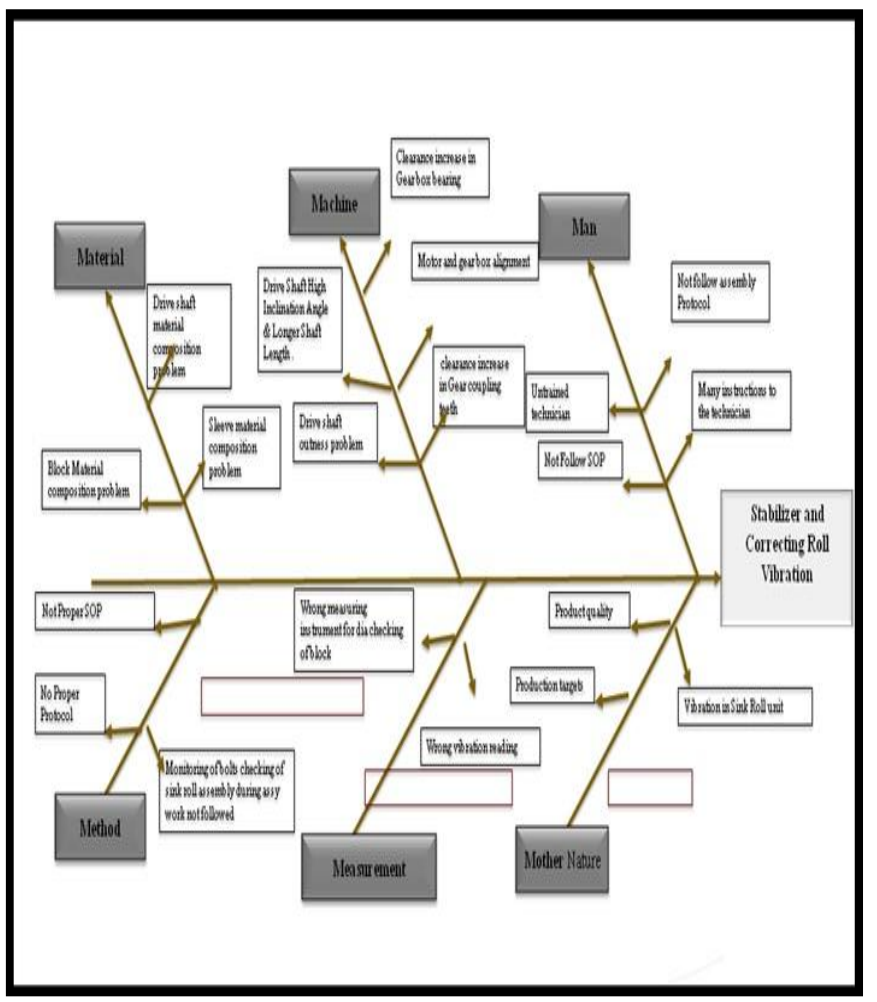

Fig 5.1: Cause and Effect diagram

Table 5.1: Vibration reading after modification

\begin{tabular}{|l|l|l|}
\hline Sl no. & Point no. & Vibration value in $\mathbf{~ m m} / \mathbf{s}$ \\
\hline 1 & Point 1 & 1.09 \\
\hline 2 & Point 2 & 1.27 \\
\hline 3 & Point 3 & 1.29 \\
\hline 4 & Point 4 & 1.19 \\
\hline
\end{tabular}

\section{RESULTS AND DISCUSSIONS}

\subsection{Cost Reduction}

For every sink roll change, complete line must be down for 4 hours. Rated capacity of CGL at JSW is $60 \mathrm{~T} / \mathrm{H}$

Conversion cost, i.e conversion of CRFH coil to Galvanized coil is Rs 3000/T

Calculation is as follows:

Sink roll changing for onetime is

$=$ CGL downtime $\mathrm{X}$ Rated capacity $\mathrm{X}$ Conversion cost

$=4 \mathrm{Hrs}$ X $60 \mathrm{~T} / \mathrm{H}$ X Rs3000/T

$=720000 /$ Sink roll assembly change

Loss due to 3 sink rolls assembly change per month = 720000 X 3 = Rs $2160000 /$ Month

Due to Quality diversion

On on an average $60 \mathrm{~T}$ per month is diverted with quality defects pertaining to scratch.
$=$ Quality diversion / Month X Conversion cost $/ \mathrm{T}$
$=60 \mathrm{~T} /$ Month X Rs 3000/T
$=$ Rs $180000 /$ Month

Cost of Consumables spares $=$ Rs $600000 /$ Month

Total cost $=29.4$ Lacs $/$ Month

After changing Stabilizer an corrector roll from drive to non drive and by changing the bush design, sink roll changing frequency have been reduced and cost benefits are

Sink roll changing for onetime is

$=$ CGL downtime X Rated capacity X Conversion cost

$=4 \mathrm{Hrs}$ X 60T/H X Rs3000/T

$=720000 /$ Sink roll assembly change

No loss with respect to quality pertaining to scratch Cost of Consumables spares $=$ Rs $200000 /$ Month Total cost $=9.2$ Lacs $/$ Month

\section{CONCLUSION}

From the results obtain it is evident that efficiency of zinc coating section of continuous galvanizing production line using quality tools has been improved and it is justified with the following statements which are compared with before and after modifications.

Corrector and Stabilizer roll drive system have been changed to non drive and sink roll bush thickness is increased to $25 \mathrm{~mm}$ (from $10 \mathrm{~mm}$ ).

- Post modification vibration reading is found to be less and roll changing frequency reduced from once in ten days to once in a month. Quality of the product is also improved.

- Costs have been reduced from 29.4 Lacs to 9.2 Lacs per month.

- A large amount of material loss, inventory loss and cost in over all have been decreased. 
- Line availability time have been increased by eight hours, as roll changing frequency have been decreased from once in 10 days( 12 hours downtime) per month to once in month ( 4 hours downtime per month. )

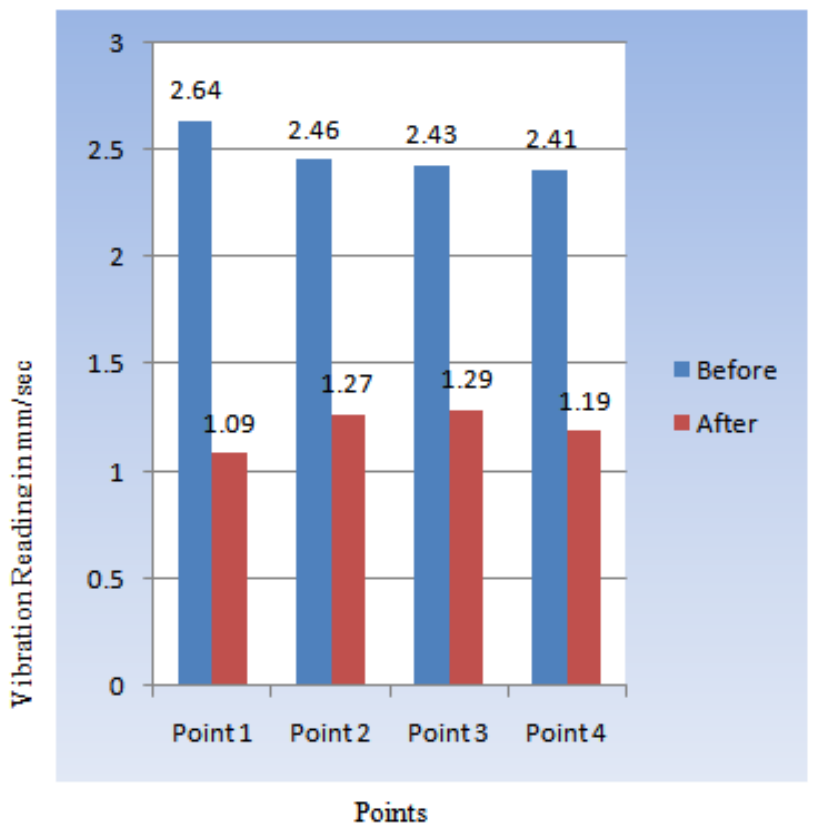

Fig 7.1: Vibration reading comparison

\section{ACKNOWLEDGEMENT}

The authors wish to thank the institution Rao Bahadur $Y$ Mahaballeshwar Engineering College and JSW Companyfor supporting us in completing the project. This project is successfully completed by the guidance of Mr. Amit Upadhay, Asst. Manager Galvanizing section, JSW Vijaynagar.

Author $^{2}$ wish to thank the principal of RYMEC BellaryDr. Hiregoudar Yerranagoudaru and Head of Dept. Mech, Dr. Kori Nagraj for permitting to carry project. And heartiest thanks to project guide and mentor Dr. Chitriki Thotappa, Professor \& M.Tech (PM) Co-ordinator for his constant guidance.

\section{REFERENCES}

[1] Pratik J. Patel: Sanjay C. Shah : Sanjay Makwana "Application of Quality Control Tools in Taper Shank Drills Manufacturing Industry: A Case Study" ISSN : 2248-9622, February 2014.

[2] Irena Ograjenšek "Applying Statistical Tools to Improve Quality in the Service Sector", Developments in Social Science Methodology, Metodološki zvezki, 18, Ljubljana: FDV, 2002

[3] Chiragkumar S. Chauhan : Sanjay C. Shah : Shrikant P. Bhatagalikar "Improvement of Productivity by application of Basic seven Quality control Tools in manufacturing industry" 2014

[4] Kazunari Andachi : Harumi Shigemoto "Method For Adjusting Coating Weight By Gas Wiping" at
Kawasaki Steel Corporation, Hyogo (Japan) US Patent (No. 5518772).

[5] Yeon Tei, Gun Young, Byung Hak \& Hae Doo "Research Paper on Method \& Apparatus For Controlling Coating Weight In Continuous Galvanizing Process" at POSCO, South Korea Published at World Intellectual Property organization

[6] Stefa'nia SalokyovaRadoslav Krehel', Martin Polla'k and Marek Koc`is"ko "Research on impacts of mechanical vibrations on the production machine to its rate of change of technical state" Advances in Mechanical Engineering 2016, Vol. 8(7) 1-10 The Author(s) 2016 DOI: 10.1177/1687814016655778

\section{BIOGRAPHIES}

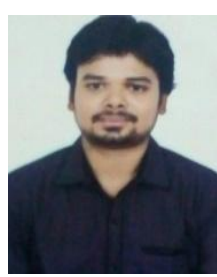

H Prashanth, (Mb.No.07353097767, Email: prashanth.haveri16@gmail.com is perusing M.tech (PM), under the guidance of Dr.C Thotappa in P.G. Studies Dept. of Mechanical Engineering at RaoBahadur $Y$ Mahaballeshwar Engineering College (RYMEC), cantonment Bellary- 583104 Karnataka. Received the B.E (Mech) degree from SDMCET, Dharwad in 2012.

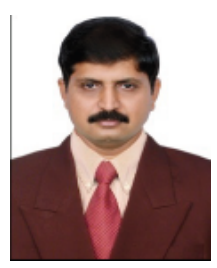

Dr. Chitriki Thotappa, (Mb.No. 09342612381, Email: thotappa@gmail.com ) is presently working as Professor \& M.Tech Coordinator, Dept. of Mechanical Engineering, at Rao Bahadur $Y$ Mahaballeshwar Engineering College (RYMEC), cantonment Bellary - 583 104, Karnataka, INDIA. He received the B.E (Mechanical) and M.E(Production Management) degrees from the Department of Mechanical Engineering from Gulbarga and Karnataka Universities, Karnataka, INDIA in 1991 and 1994 respectively, he secured his Ph.D (Supply Chain Management) in 2012 from Sri Venkateshwara collage of engineering, Tirupati-517502, Andhra Pradesh., he is having 25 years of academic experience and 8 years research experience. He has more than 16 research paper publications in International and National journals to his credit. And he is a member of Professional bodies like MISTE, MIE, MISCA and MIAENG. 